\title{
Autonomic correlates at rest and during evoked attention in children with attention-deficit/hyperactivity disorder and effects of methylphenidate
}

*Bianca Lee Negrao (MSc)

*Priyesh Bipath (MSc)

**Debbie van der Westhuizen (MD, MMed Psych)

*Margaretha Viljoen (PhD, PhD)

*Department of Physiology, School of Medicine, Faculty of Health Sciences, University of Pretoria

** Department of Psychiatry, School of Medicine, Faculty of Health Sciences, University of Pretoria

Short title / running head: Autonomic correlates in children with attentiondeficit/hyperactivity disorder

Corresponding author: Prof M Viljoen

Department of Physiology

School of Medicine

Faculty of Health Sciences

University of Pretoria

Box 2043

Pretoria

0001

Tel: (012) 3192140

Fax: (012) 3211679

E-mail: mviljoen@medic.up.ac.za 


\section{Abstract}

Objective: The aim of this study was to assess autonomic nervous system functioning in children with ADHD and to examine the effects of methylphenidate and focussed attention.

Method: Children with ADHD (n=19) were tested while they were stimulant-free and during a period in which they were on stimulants. On both occasions autonomic nervous system functioning was tested at baseline and during focussed attention. Autonomic nervous system functioning of control subjects was also tested at baseline and during focussed attention. Autonomic nervous system activity was determined by means of heart rate variability (HRV) and skin conductivity analyses. Attention was evoked by means of the BioGraph Infiniti biofeedback apparatus. HRV was determined by timedomain, frequency-domain and Poincaré analysis of RR interval data. Skin conductivity was determined by BioGraph Infiniti biofeedback apparatus.

Results: The main findings of this study were a) that stimulant-free children with ADHD showed a sympathetic under-arousal and parasympathetic over-arousal of the sympathovagal balance relative to control subjects, b) methylphenidate shifted the autonomic balance of children with ADHD towards normal levels; however a normal autonomic balance was not reached, and c) stimulant-free children with ADHD exhibited a shift in the sympathovagal balance towards the sympathetic nervous system from baseline to focussed attention; however, methylphenidate appeared to abolish this shift. Conclusions: Stimulant-free children with ADHD have a parasympathetic dominance of the autonomic balance, relative to control subjects. Methylphenidate attempts to restore 
the normal autonomic balance in children with ADHD, but inhibits the normal autonomic nervous system response to a cognitive challenge.

\section{Clinical applications}

These results indicate that methylphenidate may have a suppressive effect on the normal stress response. Although this may be of benefit to those who interact with children who suffer from ADHD, the implications for the physiological and psychological well-being of the children themselves are debatable. Further research is needed.

\section{Limitations of the study}

* Only 19 children with ADHD and 18 control subjects were tested.

* Further studies should include prior testing in order to exclude children with possible co-existing learning disabilities.

* Cognitive function and emotional responses of children with ADHD were not tested.

\section{Keywords}

ADHD, methylphenidate, Ritalin, autonomic nervous system, sympathovagal balance, heart rate variability, skin conductivity, focussed attention. 


\section{Introduction and background information}

Attention-Deficit/Hyperactivity Disorder (ADHD) is a developmental disorder [1]

characterized by inattention, hyperactivity and impulsivity [2]. ADHD is found in every ethnic and socio-economic group [3] with a prevalence of 3-5\% of school-age children, according to the fourth edition of the Diagnostic and Statistical Manual of Mental Disorders (DSM-IV) [2]. This makes ADHD the most prevalent psychiatric disorder of childhood [4].

Although the cause of ADHD is not completely understood, research into the condition has identified various possible contributing factors such as nutrition, social environment (including early problems in parental attachment, prenatal alcohol or tobacco exposure and premature delivery), toxic chemicals (such as lead) and pharmaceuticals (such as anticonvulsants), as well as inherent physical disorders such as metabolic, neuroanatomical and neurochemical deficits [5]. It is plausible that the aetiology of ADHD is not one dimensional, but instead involves various neuroanatomical and neurochemical systems [5], with the main abnormalities believed to be catecholaminergic, specifically dopaminergic, and frontostriatal dysfunction [6]. Although the roles of both dopamine and noradrenaline in the aetiology of ADHD have been well-documented [7, 8, 9], focus on a possible role for serotonin has recently increased, with some studies showing a link between certain serotonin receptor genes and ADHD susceptibility [10, 11, 12]. The link between serotonin and ADHD appears to lie in aggression, with low levels of serotonin associated with impulsivity, aggressive behaviours and disinhibition [13, 14, 15, 16]. An interesting theory is that by Oades, which states that it is not the absolute 
level of a specific neurotransmitter which elicits the symptoms of ADHD but rather the relationship of the monamines to each other which is significant [17]. In particular, this theory states that dopaminergic activity is high with respect to noradrenaline metabolism, but low with respect to serotonin metabolism [17].

Various tests are used for the identification of ADHD; however no standardized, established, diagnostic laboratory test exists [2]. Currently, diagnosis of ADHD involves behavioural descriptors that inevitably overlap with a range of other disorders [18]. Furthermore, these interview and rating scales are often confounded by rater bias [19]. Although neuropsychological attention measures, such as continuous performance tests administered and scored by computers, are considered more objective measures of inattention and impulsivity, they tend to yield a high rate of false negatives [19]. Furthermore, diagnosis of ADHD is complicated by the fact that none of the core symptoms are exclusive to the disorder and that the majority of sufferers have additional psychiatric disorders [20].

Abnormal catecholaminergic functioning is, as previously mentioned, accepted as a central contributing factor to the development of ADHD. With regards to the autonomic nervous system, indications are that sympathetic under-arousal exists in children with ADHD [21, 22, 23, 24]. This is supported by the fact that adrenergic stimulants, which have been shown to increase the concentration of dopamine and noradrenaline in the synapse [25, 26], are the medication of choice for ADHD. Very little attention has been given to the parasympathetic nervous system in ADHD with the result that no conclusion 
on the autonomic (sympathetic/parasympathetic) balance of these patients has been reached. Further studies, not only on baseline sympathetic activity, parasympathetic activity and autonomic balance, but also on the effects of adrenergic stimulants and focussed attention on autonomic nervous system functioning, are necessary.

If the standard physiological autonomic profile, coupled with neurological and psychiatric indices, of ADHD individuals can be established, it could help to pave the way for the development of a diagnostic test for one of the most easily misdiagnosed diseases. The aim of this study, therefore, was to investigate autonomic nervous system functioning of children with ADHD, as compared to control subjects; as well as to examine the effects of methylphenidate and focussed attention on this system.

As previously mentioned, it is known that stimulants such as methylphenidate function by increasing the amount of dopamine and noradrenaline in the synapse [25, 26], therefore we hypothesized that stimulant usage will shift the sympathovagal balance of children with ADHD towards the sympathetic nervous system. Furthermore, since the usual response to a cognitive stressor is a shift in the autonomic balance towards the sympathetic nervous system [27]; we hypothesized that focussed attention will cause a shift in the sympathovagal balance towards the sympathetic nervous system in controls and stimulant-free children with ADHD. However, how methylphenidate will affect this shift is unknown. 


\section{Methods}

The study protocol was submitted to and approved by the Faculty of Health Sciences Research Ethics Committee, University of Pretoria, clearance number S30/2007, and conducted in accordance with the Declaration of Helsinki and CGP/ICH guidelines. The protocol was, furthermore, submitted to and approved by the South African Department of Health, DOH trial number DOH-27-0808-1816. Patient recruitment and supervision was conducted by a registered psychiatrist involved in the study. Only children from whom and from whose guardians/parents voluntary informed consent could be obtained were included in the study.

\section{Subjects}

The experimental group consisted of 19 children diagnosed with ADHD by a registered psychiatrist, according to the text revised Fourth Edition of the Diagnostic and Statistical Manual of Mental Disorders (DSM-IV-TR) (13 boys and 6 girls, ages 6 to 15 years, mean 9.53 years). Exclusion criteria included children with co-morbidities such as conduct disorder, children on medication other than methylphenidate (including other stimulants as well as medications known to affect the autonomic nervous system), overtly malnourished children, mentally retarded children and children with the inability to understand and give informed assent. Children were also excluded if informed consent could not be obtained from their parent or guardian. The children with ADHD were regarded as being on medication if they had been taking methylphenidate (Ritalin) consistently for at least 10 days at the dosage prescribed specifically for them by their psychiatrist. Eighteen of the children with ADHD tested in our study were taking short- 
acting methylphenidate at a dosage of $10 \mathrm{mg}$, while one child was on long-acting methylphenidate at a dosage of $20 \mathrm{mg}$. These same children were tested after they had refrained from taking methylphenidate for a period of about three weeks during their school holiday and were then considered to be stimulant-free. The practise of taking children with ADHD off their stimulant medication during their school holidays is normal and was not introduced into the treatment regime as part of the study. The control group consisted of 18 age- and sex-matched control subjects (12 boys and 6 girls, 7 to 13 years, mean 9.17 years) who did not have any psychiatric illnesses, were not on any medication, were not overtly malnourished, were not mentally retarded and could understand and give informed assent. Informed consent was also obtained from all the parents/guardians of the control subjects. Table 1 represents the demographic data of the children with ADHD and control subjects.

\section{Autonomic nervous system functioning}

Autonomic nervous system functioning of all children was assessed by means of both heart rate variability (HRV) and skin conductivity recordings. All children were tested at baseline and during focussed attention. Children with ADHD were tested while they were stimulant-free and during a period in which they were on stimulant medication, while control subjects were tested once. HRV and skin conductivity data was sampled while the children were sitting in a quiet environment at a constant room temperature. Baseline recordings were made over a period of 5 minutes. The 5 minute baseline recordings were directly followed by 10 minute recordings during focussed attention. Focussed attention was evoked by means of a program on the BioGraph Infiniti 
biofeedback apparatus which has been developed specifically as a mechanism to train individuals with ADHD to increase their attentive abilities. This program extracts electroencephalography (EEG) frequency components and feeds them back in the form of a game, using an audio-visual loop. The specific biofeedback program that was used was a bowling EEG speed game. This program allows subjects to move a bowling ball down an alley as long as two essential criteria are met, i.e. sensorimotor rhythm (SMR) enhancement and theta suppression. In other words, the bowling ball only moved down the alley when the children were able to keep their SMR 13-15 Hz activity above a predetermined threshold and their theta 3-7 Hz activity below a pre-determined threshold.

\section{Heart rate variability recordings}

HRV was determined by analysis of the RR interval data sets (tachograms), which were obtained by POLAR NV heart rate monitors. Five minute recordings were analysed. The full 5 minute baseline HRV recordings and the middle 5 minutes of the 10 minute HRV recordings during focussed attention were analysed for this study. The data (RR interval sets) were analysed using HRV Analysis Software 1.1 for Windows, developed by The Biomedical Signal Analysis Group, Department of Applied Physics, University of Kuopio, Finland. Smoothness priors for Trend and Model Eye program settings were used for de-trending, with an alpha value of 500. An auto regressive model order value of 16 and an interpolation rate of $4 \mathrm{~Hz}$ were used. Error correction of a moderate filter power and minimum protection zone of 6 beats per minute was applied to the raw tachograms. In four of the HRV recordings, extreme outliers had to be removed manually before the error correction could be performed. The techniques used for the 
evaluation of HRV from the RR interval data sets, were grouped into three categories: time domain, frequency domain and non-linear analysis. Table 2 represents the HRV indicators used in this study as well as the key for all abbreviations. The time-domain indicators used in this study included mean heart rate, which is an indicator of sympathovagal balance; STDRR and HRV triangular index, which are indicators of global heart rate variability [28]; STDHR, which is a measure of the long-term components of heart rate variability [28]; and RMSSD, which is an indicator of parasympathetic nervous system activity [29]. The frequency-domain indicators used included the high frequency component (HF) at 0.15 to $0.40 \mathrm{~Hz}$, the low frequency component (LF) at 0.04 to $0.15 \mathrm{~Hz}$ and the LF/HF ratio. HF is an indication of parasympathetic nervous system activity [30, 31, 32, 33], while the autonomic contributions to the LF component are still being investigated and no consensus currently exists. The LF component is said to provide information on sympathetic activity but with notable influences from the parasympathetic nervous system, baroreceptor feedback and brainstem rhythms [34]. However, the LF component is considered by some a definite marker of sympathetic activity when expressed in normalized units [28, 35]. Therefore, HF and LF were measured in both absolute power $\left(\mathrm{ms}^{2}\right)$ and normalized units (nu) in this study. The LF/HF ratio was investigated as a measure of sympathovagal balance [30, 31, 32, 33, 34, 36, 37], whereby an increase in the LF/HF ratio indicates a dominance of sympathetic activity and a decrease in the LF/HF ratio indicates parasympathetic predominance [29]. The Poincaré plot indicators used included SD1, which is an indicator of short term variability in heart rate, representing parasympathetic nervous system activity on the sinus node [27]; and SD2, which reflects global heart rate 
variability as an inverse function of sympathetic modulation [34]. In other words, SD2 is believed to be an inverse measure of sympathetic activity [34], whereby an increase in SD2 represents an increase in global heart rate variability which, in turn, reflects a decrease in sympathetic activity. Therefore, an increase in SD2 represents a decrease in sympathetic nervous system activity and vice versa.

\section{Skin conductivity recordings}

Skin conductivity was determined by means of the BioGraph Infiniti biofeedback apparatus. The skin conductivity signal was collected through two silver-silver chloride electrodes attached by adhesive collars to the palmar surface of the middle and index fingers of the left hand. Subjects were asked to wash their hands with soap and dry them prior to sampling to ensure the removal of surface salt. The BioGraph Infiniti biofeedback program used to measure skin conductivity contains an assessment program which automatically provided us with the skin conductivity values (in $\mu$ Mhos) of the participants. Skin conductivity is the measurement of the electrical conductance of the skin as a result of eccrine sweat gland activity [38]. Since the eccrine sweat glands are innervated by the sympathetic nervous system, with no parasympathetic input, skin conductivity reflects sympathetic nervous system activity exclusively [21].

\section{Statistics}

All data was statistically analysed using Stata ${ }^{\mathrm{TM}}$ Data Analysis Software. Due to the nature of the distribution, the Mann-Whitney and Wilcoxon signed-rank tests for nonparametric data were used. The Mann-Whitney test was used when comparing values 
obtained for the children with ADHD to those obtained for the control subjects. When comparing values obtained while the children with ADHD were on stimulant medication to those obtained while they were stimulant-free, the Wilcoxon signed-rank test was used. Furthermore, the Wilcoxon signed-rank test was also used when comparing values at baseline and values during focussed attention for the same participant. The results did not receive any corrections in terms of alpha-adjustment due to the explorative nature of the investigation.

\section{Results}

The demographic data of the research candidates is represented in Table 1.

\section{Baseline heart rate variability}

When comparing baseline HRV between stimulant-free children with ADHD and control subjects, statistically significant differences were found for mean HR $(P=0.02)$, STDRR ( $P=0.008)$, RR triangular index $(P=0.002)$, STDHR $(P=0.02), \operatorname{RMSSD}(P=0.02), \operatorname{LF}\left(\mathrm{ms}^{2}\right)$ $(P=0.02)$, SD1 $(P=0.02)$ and SD2 $(P=0.006)$ (see Table 3. When comparing baseline HRV between children with ADHD on stimulant medication and control subjects, a statistically significant difference in SD2 $(P=0.04)$ was found (see Table 4). [Insert Table 4]. When comparing baseline HRV between stimulant-free children with ADHD and children with ADHD on stimulant medication, statistically significant differences were found for mean HR ( $P=0.003)$, STDRR $(P=0.04)$ and RR triangular index $(P=0.003)$ (see Table 5). 


\section{Baseline skin conductivity}

When comparing baseline skin conductivity between stimulant-free children with ADHD and control subjects, a marginally statistically significant difference $(P=0.08)$ was found, with skin conductivity found to be lower in stimulant-free children with ADHD (1.35 \pm $0.83 \mu$ Mhos vs. $1.96 \pm 1.00 \mu$ Mhos) (see Table 6). When comparing baseline skin conductivity between children with ADHD on stimulant medication and control subjects, no statistically significant differences were found (see Table 6). A statistically significant difference in baseline skin conductivity $(P=0.006)$ was found when comparing the values obtained while the children with ADHD were on stimulant medication to those obtained while they were stimulant-free, with baseline skin conductivity found to be higher in children with ADHD while they were on stimulant medication (2.21 $\pm 1.14 \mu$ Mhos vs. $1.35 \pm 0.83 \mu$ Mhos) (see Table 6).

\section{Difference in HRV between baseline and focussed attention}

Regarding the control subjects, a statistically significant difference between baseline and focussed attention was found for $\operatorname{HF}\left(\mathrm{ms}^{2}\right)(P=0.03)$, with $\mathrm{HF}\left(\mathrm{ms}^{2}\right)$ found to decrease from baseline to focussed attention (435.67 $\pm 595.03 \mathrm{~ms}^{2} v s .275 .17 \pm 410.86 \mathrm{~ms}^{2}$ ) (see Figure 1). In the stimulant-free children with ADHD, statistically significant differences between baseline and focussed attention were found for mean HR $(P=0.001)$, RMSSD ( $P=0.004), \operatorname{HF}\left(\mathrm{ms}^{2}\right)(P=0.01)$, HFnu $(P=0.03)$, LFnu $(P=0.03)$ and SD1 $(P=0.004)$, with mean HR (87.67 \pm 7.75 bpm vs. $90.43 \pm 8.84$ bpm) and LFnu (48.06 \pm 16.82 nu vs. 55.78 $\pm 16.80 \mathrm{nu}$ ) increasing from baseline to focussed attention and RMSSD (52.51 \pm 21.95 msec vs. $45.04 \pm 18.24 \mathrm{msec})$, HFnu (51.94 $\pm 16.82 \mathrm{nu}$ vs. $44.22 \pm 16.80 \mathrm{nu})$, SD1 (37.36 
\pm 15.59 msec vs. $32.07 \pm 12.95 \mathrm{msec})$ and $\mathrm{HF}\left(\mathrm{ms}^{2}\right)\left(659.16 \pm 505.75 \mathrm{~ms}^{2}\right.$ vs. $512.37 \pm$ $411.62 \mathrm{~ms}^{2}$ ) (see Figure 1), decreasing from baseline to focussed attention. Regarding the children with ADHD on stimulant medication, no statistically significant differences in HRV parameters between baseline and focussed attention were found (see Figure 1). It is important to note here that that although the mean HF increased from baseline to focussed attention in the ADHD children on stimulant medication, as evident in Figure 1, the increase was not statistically significant ( $P=0.38$ for $\mathrm{HFms}^{2}$ and $P=0.16$ for HFnu) due to the wide standard deviation of the data.

\section{Difference in skin conductivity between baseline and focussed attention}

In the control subjects a statistically significant increase in skin conductivity $(P=0.003)$ from baseline to focussed attention (1.96 $\pm 1.00 \mu$ Mhos vs. $2.43 \pm 1.27 \mu$ Mhos) was found (see Figure 2). Regarding the stimulant-free children with ADHD, a statistically significant increase in skin conductivity $(P=0.003)$ from baseline to focussed attention was found (1.35 $\pm 0.83 \mu$ Mhos vs. $1.68 \pm 1.08 \mu$ Mhos) (see Figure 2). However, regarding the children with ADHD on stimulant medication, no statistically significant difference in skin conductivity between baseline and focussed attention was found (see Figure 2).

\section{Discussion}

Indications are that sympathetic under-arousal exists in children with ADHD [21, 22, 23, 24]. Published results are, however, controversial. Most studies only use one measure to determine sympathetic nervous system activity, very few studies measure sympathetic 
nervous system functioning while participants are both on stimulants and stimulant-free, and the majority of research is conducted without examining the relationship between autonomic nervous system functioning and focussed attention. The latter is a major oversight as the inability to focus attention represents one of the major problems of ADHD. In addition, very little is known about parasympathetic nervous system functioning in ADHD. While Crowell et al [24] found that children with ADHD do not differ from control subjects with regards to parasympathetic nervous system activity; results from the study by Shibagaki and Furuya [39] suggested that children with ADHD display a level of parasympathetic under-arousal. What is overlooked is the fact that the functional outcome is dependent on the autonomic balance, rather than merely sympathetic or parasympathetic activation. The present study investigated the autonomic nervous system functioning of children with ADHD, as compared to control subjects, and examined the effects of methylphenidate and focussed attention on this system.

\section{Baseline autonomic nervous system activity}

Stimulant-free children with ADHD versus control subjects

In the present study HRV analyses indicated that stimulant-free children with ADHD have a level of sympathetic under-arousal relative to control subjects, as suggested by their higher SD2 values (see Table 3). Since skin conductivity reflects the output of the sympathetic nervous system to the sweat glands, this finding was supported by skin conductivity levels, which indicated that stimulant-free children with ADHD display a lower level of skin conductivity than control subjects (see Table 6). HRV analyses, moreover, indicated that stimulant-free children with ADHD exhibit a higher degree of 
parasympathetic tone than control subjects, as indicated by the higher RMSSD and SD1 values found in the stimulant-free children with ADHD (see Table 3). HRV and skin conductivity analyses, therefore, indicated that stimulant-free children with ADHD demonstrate a parasympathetic dominance of the sympathovagal balance relative to control subjects. This relative parasympathetic dominance of the sympathovagal balance in stimulant-free children with ADHD was confirmed by the higher overall heart rate variability (reflected by higher STDRR, RR triangular index, STDHR and SD2) and the lower HR found in these children (see Table 3). As previously mentioned, low levels of serotonin have been associated with impulsivity, aggressive behaviours and disinhibition $[13,14,15,16]$. Interestingly, a recent study by Zept et al found that a decrease in serotonin in children with ADHD results in an increase in aggression and a concomitant decrease in HR [40]. It is therefore very interesting to note that children with ADHD, who are generally more impulsive and aggressive than controls, have been found to have a lower resting HR than control subjects. These results do not support the parasympathetic nervous system findings from Crowell et al [24], which indicate that stimulant-free children with ADHD do not differ from age-matched controls with regards to parasympathetic nervous system activity; or the results from Shibagaki and Furuya [39], which suggest that children with ADHD display an under-activity of the parasympathetic nervous system when compared to controls. A possible reason for the difference in findings from those of Crowell et al could be that Crowell et al simply looked at the high frequency component of HRV as a measure of parasympathetic nervous system activity in their patients [24]. Interestingly, our stimulant-free children with ADHD were not found to differ from controls with regards to the HF component of 
HRV (see Table 3). Therefore, based on HF results alone this study would also not have found a difference in parasympathetic activity between stimulant-free children with ADHD and controls. The results do, however, support the sympathetic nervous system findings of Crowell et al [24] which found sympathetic under-arousal in stimulant-free ADHD children, as assessed by electrodermal responses and cardiac pre-ejection periods; and that of Beauchaine et al [21], which, similarly, found sympathetic under-arousal in stimulant-free children with ADHD, as assessed by means of electrodermal responses.

\section{Children with ADHD on stimulant medication versus control subjects}

As will be discussed in a later paragraph, where a comparison between stimulant-free children and children on methylphenidate is made, methylphenidate was seen to have a stimulatory effect on the sympathetic nervous system activity of children with ADHD. However, the HRV analyses of this study further revealed that children with ADHD on stimulant medication still displayed an under-activity of the sympathetic nervous system relative to control subjects, as reflected by their higher SD2 values (see Table 4). Regarding parasympathetic nervous system activity, HRV analyses showed that children with ADHD, while on stimulant medication, did not appear to differ from control subjects with regard to their parasympathetic tone (see Table 4). These findings suggest that methylphenidate attempts to normalize the autonomic balance of children with ADHD; however a normal sympathovagal balance does not appear to be reached in these children since the level of sympathetic arousal in ADHD children on stimulant medication is still found to be lower than that of the control subjects. 
Effect of focussed attention on the autonomic nervous system

Analyses indicated that control subjects and stimulant-free children with ADHD exhibit a shift in the sympathovagal balance towards the sympathetic nervous system from baseline to focussed attention. This is the expected reaction of the autonomic nervous system to a psychological or cognitive stressor [27]. In control subjects, the shift in the sympathovagal balance towards the sympathetic nervous system from baseline to focussed attention was reflected by a significant decrease in $\mathrm{HF}\left(\mathrm{ms}^{2}\right)$, which suggests a decrease in parasympathetic activity, and a significant increase in skin conductivity, which indicates an increase in sympathetic activity (see Figure 1 and 2). In the stimulantfree children with ADHD, the shift in the sympathovagal balance towards the sympathetic nervous system from baseline to focussed attention was reflected by significant decreases in RMSSD, $\mathrm{HF}\left(\mathrm{ms}^{2}\right.$ ) (see Figure 1), HFnu and SD1, which suggests a decrease in parasympathetic activity, as well as significant increases in LFnu and skin conductivity (see Figure 2), which suggests an increase in sympathetic activity.

Furthermore, this shift towards the sympathetic nervous system in stimulant-free children with ADHD was confirmed by the increase in HR found in these children.

Effect of sympathomimetic medication on the autonomic nervous system The skin conductivity analyses of this study suggested that children with ADHD on stimulant medication demonstrate a higher level of sympathetic tone than stimulant-free children with ADHD (see Table 5). In view of the fact that parasympathetic tone was significantly higher in the stimulant-free children with ADHD than in the control subjects, and that this difference between control subjects and children with ADHD was abolished 
when they were put on methylphenidate, parasympathetic tone must have, to some degree, been decreased by methylphenidate. These results suggest that children with ADHD demonstrated a shift in the sympathovagal balance from a relative parasympathetic dominance when stimulant-free towards the sympathetic nervous system when on stimulant medication. This sympathetic dominance of the autonomic balance in children with ADHD on stimulant medication, relative to stimulant-free children with ADHD, was confirmed by the lower overall heart rate variability (as reflected by lower STDRR and RR triangular index) and the higher HR found in the children when on stimulant medication (see Table 5). These results, therefore, confirm the sympathomimetic properties of noradrenergic stimulants.

Regarding the effect of sympathomimetic medication on the stress response from baseline to focussed attention, children with ADHD on stimulant medication displayed no shift in the sympathovagal balance from baseline to focussed attention as reflected by the lack of differences in both HRV parameters and skin conductivity in these children (see Figure 1 and 2). These results suggest that methylphenidate suppresses the ability of the sympathetic nervous system to react to a cognitive stressor.

\section{Conclusions}

Stimulant-free children with ADHD demonstrated a baseline parasympathetic dominance of the autonomic nervous system balance relative to control subjects. This relative parasympathetic dominance of the sympathovagal balance in stimulant-free children with ADHD seemed to occur as a result of parasympathetic over-activity as well as 
sympathetic under-activity. Methylphenidate appeared to shift the autonomic balance of children with ADHD towards normal levels by seemingly increasing their low sympathetic activity and decreasing their parasympathetic over-activity. However, indications are that a normal autonomic balance was not reached in these children as they still demonstrated a level of sympathetic under-arousal relative to control subjects. Stimulant-free children with ADHD demonstrated the expected sympathovagal shift towards the sympathetic nervous system when presented with a cognitive challenge; however methylphenidate appeared to abolish this reactivity of the autonomic nervous system. This could have negative implications for the psychological and physiological well-being of these children.

\section{Funding and Support}

This research was supported by a grant from NAVKOM, School of Medicine, University of Pretoria.

\section{Acknowledgements}

Mrs M Crafford for her technical assistance. Mr F de Jager, Sister NH Steyn, Mr R Beech and Mrs R Ras for their help in recruiting participants. Prof PJ Becker for his assistance in the statistical analysis. 


\section{References}

1. Panzer A, Viljoen M, 2005. Supportive neurodevelopmental evidence for ADHD as a developmental disorder. Med. Hypotheses 64:755-8

2. American Psychiatric Association, 2000. Diagnostic and statistical manual of mental disorders, $4^{\text {th }}$ edn. Washington DC, American Psychiatric Association

3. ADHASA, 2008. ADHASA South Africa, viewed 20 Jan 2008, $<$ http://www.adhdsupport.co.za>.

4. Mill J, 2007. Rodent models: utility for candidate gene studies in human Attention-Deficit Hyperactivity Disorder (ADHD). J. Neurosci. Methods 166:294-305

5. Sadock BJ, Sadock VA (Eds). Kaplan and Sadock's comprehensive textbook of psychiatry, $8^{\text {th }}$ edn. Philadelphia, Lippincott Williams \& Wilkins

6. Spencer TJ, Biederman J, Madras BK, Faraone SV, Dougherty DD, Bonab AA, Fischman AJ, 2005. In vivo neuroreceptor imaging in Attention-

Deficit/Hyperactivity Disorder: a focus on the dopamine transporter. Biol. Psychiatry 57:1293-300

7. Hechtman L, 1994. Genetic and neurobiological aspects of attention deficit hyperactivity disorder: a review. J Psychiatr Neurosci 19:193-201

8. Levy F, 1991. The dopamine theory of attention deficit hyperactivity disorder (ADHD). Aust N Z J Psychiatry 25:277-83

9. Oades RD, 1987. Attention-deficit disorder with hyperactivity: the contribution of catecholaminergic activity. Prog Neurobiol 29:365-91

10. Guimarães AP, Schmitz M, Polanczyk GV, Zeni C, Genro J, Roman T, Rohde LA, Hutz MH, 2009. Further evidence for the association between attention deficit/hyperactivity disorder and the serotonin receptor $1 \mathrm{~B}$ gene. J Neural Transm 116(12):1675-80

11. Li J, Wang Y, Zhou R, Wang B, Zhang H, Yang L, Faraone S, 2006. Association of attention-deficit/hyperactivity disorder with serotonin 4 receptor gene polymorphisms in Han Chinese subjects. Neurosci Lett 401(1-2):6-9

12. Li J, Wang Y, Zhou R, Zhang H, Yang L, Wang B, Faraone S, 2006. Association between polymorphisms in serotonin $2 \mathrm{C}$ receptor gene and attentiondeficit/hyperactivity disorder in Han Chinese subjects. Neurosci Lett 407(2):10711

13. Stadler C, Zepf FD, Demisch L, Schmitt M, Landgraf M, Poustka F, 2007. Influence of rapid tryptophan depletion on laboratory-provoked aggression in children with ADHD. Neuropsychobiology 56(2-3):104-10

14. Zepf FD, Stadler C, Demisch L, Schmitt M, Landgraf M, Poustka F, 2008. Serotonergic functioning and trait-impulsivity in attention-deficit/hyperactivitydisordered boys (ADHD): influence of rapid tryptophan depletion. Hum Psychopharmacol 23(1):43-51

15. Zepf FD, Holtmann M, Stadler C, Demisch L, Schmitt M, Wöckel L, Poustka F, 2008. Diminished serotonergic functioning in hostile children with ADHD: tryptophan depletion increases behavioural inhibition. Pharmacopsychiatry 41(2):60-5 
16. Guimarães AP, Zeni C, Polanczyk GV, Genro JP, Roman T, Rohde LA, Hutz MH, 2007. Serotonin genes and attention deficit/hyperactivity disorder in a Brazilian sample: preferential transmission of the HTR2A 452His allele to affected boys. Am J Med Genet B Neuropsychiatr Genet 144B(1):69-73

17. Oades RD, 2002. Dopamine may be 'hyper' with respect to noradrenaline metabolism, but 'hyp' with respect to serotonin metabolism in children with attention-deficit hyperactivity disorder. Behav Brain Res 130:97-102

18. Nigg JT, 2005. Neuropsychologic theory and findings in Attention-DeficitHyperactivity Disorder: the state of the field and salient challenges for the coming decade. Biol. Psychiatry 57:1424-35

19. Monastra VJ, Lubar JF, Linden M, 2001. The development of a Quantitative Electroencephalographic scanning process for Attention Deficit-Hyperactivity Disorder: reliability and validity studies. Neuropsychology 15(1):136-44

20. Rossiter T, 2004. The effectiveness of neurofeedback and stimulant drugs in treating AD/HD: Part II. Replication. Appl. Psychophysiol. Biofeedback 29(4):233-43

21. Beauchaine TP, Katkin ES, Strassberg Z, Snarr J, 2001. Disinhibitory psychopathology in male adolescents: discriminating Conduct Disorder from Attention-Deficit/Hyperactivity Disorder through concurrent assessment of multiple autonomic states. J. Abnorm. Psychol. 110(4):610-24

22. O’Connell RG, Bellgrove MA, Dockree PM, Robertson IH, 2004. Reduced electrodermal response to errors predicts poor sustained attention performance in Attention Deficit Hyperactivity Disorder. Neuroreport 15(16):2535-8

23. Broyd SJ, Johnstone SJ, Barry RJ, Clarke AR, McCarthy R, Selikowitz M, 2005. The effect of methylphenidate on response inhibition and the event-related potential of children with Attention Deficit/Hyperactivity Disorder. Int. J. Psychophysiol. 58:47-58

24. Crowell SE, Beauchaine TP, Gatzke-Kopp L, Sylvers P, Mead H, ChipmanChacon J, 2006. Autonomic correlates of Attention-Deficit/Hyperactiviy Disorder and Oppositional Defiant Disorder in preschool children. J. Abnorm. Psychol. 115(1):174-8

25. Vles JS, Feron FJ, Hendriksen JG, Jolles J, van Kroonenburgh MJ, Weber WE, 2003. Methylphenidate down-regulates the dopamine receptor and transporter system in children with attention deficit hyperkinetic disorder (ADHD). Neuropedicatrics 34(2):77-80

26. Carboni E, Silvagni A, 2004. Experimental investigations on dopamine transmission can provide clues on the mechanism of the therapeutic effect of amphetamine and methylphenidate in ADHD. Neural Plast. 11(1-2):77-95

27. Grant CC, 2005. Heart rate variability and dysrhythmogenic potential in patients admitted to psychiatric institutions. Dissertation, University of Pretoria

28. Task Force of The European Society of Cardiology and The North American Society of Pacing and Electrophysiology, 1996. Heart rate variability Standards of measurement, physiological interpretation, and clinical use. Eur. Heart J 17:35481

29. Hubeaux K, Deffieux X, Ismael SS, Raibaut P, Amarenco G, 2007. Autonomic Nervous System Activity During Bladder Filling Assessed by Heart Rate 
Variability Analysis in Women with Idiopathic Overactive Bladder Syndrome or Stress Urinary Incontinence. J. Urol. 178:2483-7

30. Lewis MJ, Kinsley M, Short AL, Simpson K, 2007. Influence of high-frequency bandwidth on heart rate variability analysis during physical exercise. Biomedical Signal Processing and Control 2:34-9

31. Hallioglu O, Okuyaz C, Mert E, Makharoblidze K, 2008. Effects of antiepileptic drug therapy on heart rate variability in children with epilepsy. Epilepsy Res. 79:49-54

32. Tsou C, Kao T, Fan K, Wang J, Luk H, Koenig HM, 2008. Clinical assessment of propofol-induced yawning with heart rate variability: a pilot study. J. Clin. Anesth. 20:25-9

33. Haensch C, Lerch H, Jörg J, Isenmann S, 2009. Cardiac denervation occurs independent of orthostatic hypotension and impaired heart rate variability in Parkinson's disease. Parkinsonism Relat. Disord. 15(2):134-7

34. Craig J, 2005. The psychoneurological profile of Fibromyalgia. Dissertation, University of Pretoria

35. Harnod T, Yang CCH, Hisn Y, Shieh K, Wang P, Kuo TBJ, 2008. Heart rate variability in children with refractory generalized epilepsy. Seizures 17:297-301

36. Kishore KR, Udupa K, Gangadhar BN, Lavekar GS, Raju TR, Sathyaprabha TN, 2008. Differential effect of ayurveda (Indian traditional system of medicine) and tricyclic antidepressants in altering cardiac autonomic functions in patients of major depression - A clinical study with heart rate variability (HRV) measures. J. Affect. Disord. 107:S53-122

37. Castro MN, Vigo DE, Weidema H, Fahrer RD, Chu EM, de Achával D, Nogués M, Leiguarda RC, Cardinali DP, Guinjoan SM, 2008. Heart rate variability response to mental arithmetic stress in patients with schizophrenia Autonomic response to stress in schizophrenia. Schizophr. Res. 99:294-303

38. Schaaf RC, Miller LJ, Seawell D, O’Keefe S, 2003. Children With Disturbances in Sensory Processing: A Pilot Study Examining the Role of the Parasympathetic Nervous System. Am. J. Occup. Ther. 57:442-9

39. Shibagaki M, Furuya T, 1997. Baseline respiratory sinus arrhythmia and heartrate responses during auditory stimulation of children with Attention-Deficit Hyperactivity Disorder. Percept. Mot. Skills 84(3 Pt 1):967-75

40. Zepf FD, Holtmann M, Stadler C. Wöckel L, Poustka F, 2009. Reduced serotonergic functioning changes heart rate in ADHD. J Neural Transm 116:105-8 
Table 1 Demographic data of children with ADHD and control subjects

\begin{tabular}{|c|c|c|c|c|c|c|}
\hline \multicolumn{7}{|c|}{ ADHD group } \\
\hline & $\begin{array}{l}\text { Age } \\
\text { (years) }\end{array}$ & $\begin{array}{l}\text { Height } \\
\text { (m) }\end{array}$ & $\begin{array}{l}\text { Weight } \\
\text { (kg) }\end{array}$ & W:H & Boys & Girls \\
\hline Mean & 9.53 & 1.41 & 37.07 & 0.88 & 13 & 6 \\
\hline SD & 2.12 & 0.13 & 10.18 & 0.064 & & \\
\hline \multicolumn{7}{|c|}{ Control group } \\
\hline & $\begin{array}{l}\text { Age } \\
\text { (years) }\end{array}$ & $\begin{array}{l}\text { Height } \\
\text { (m) }\end{array}$ & $\begin{array}{l}\text { Weight } \\
\text { (kg) }\end{array}$ & $\mathbf{W}: \mathbf{H}$ & Boys & Girls \\
\hline Mean & 9.17 & 1.41 & 37.37 & 0.89 & 12 & 6 \\
\hline SD & 1.42 & 0.09 & 11.48 & 0.072 & & \\
\hline
\end{tabular}


Table 2 HRV variables used in this study

PNS, parasympathetic nervous system; SNS, sympathetic nervous system

\begin{tabular}{|c|c|c|c|}
\hline & Indicator & Explanation & Represents \\
\hline \multirow{5}{*}{ 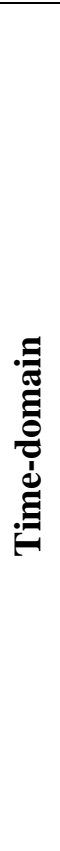 } & Mean HR & Average heart rate in beats per minute (bpm) & $\begin{array}{l}\text { Sympathovagal } \\
\text { balance }\end{array}$ \\
\hline & STDRR & $\begin{array}{l}\text { Standard deviation in the normal RR-interval in seconds } \\
\text { (sec) }\end{array}$ & Global HRV \\
\hline & $\begin{array}{l}\text { RR triangular } \\
\text { index }\end{array}$ & $\begin{array}{l}\text { The base of the triangular area under the main peak of } \\
\text { the RR interval frequency distribution diagram }\end{array}$ & Global HRV \\
\hline & STDHR & $\begin{array}{l}\text { Standard deviation of the selected heart rate series in } \\
\text { bpm }\end{array}$ & $\begin{array}{l}\text { Long-term } \\
\text { components of HRV }\end{array}$ \\
\hline & RMSSD & $\begin{array}{l}\text { Square root of the mean squared differences of } \\
\text { successive RR intervals in milliseconds (msec) }\end{array}$ & PNS \\
\hline \multirow{5}{*}{ 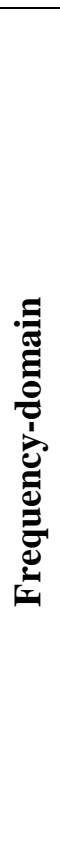 } & HF & $\begin{array}{l}\text { Spectral power in the high frequency range of } 0.15- \\
0.40 \mathrm{~Hz}\left(\mathrm{~ms}^{2}\right)\end{array}$ & PNS \\
\hline & LF & $\begin{array}{l}\text { Spectral power in the low frequency range of } 0.04-0.15 \\
\mathrm{~Hz}\left(\mathrm{~ms}^{2}\right)\end{array}$ & $\begin{array}{l}\text { SNS with PNS } \\
\text { influence }\end{array}$ \\
\hline & HFnu & $\begin{array}{l}\text { Spectral power in the high frequency range in } \\
\text { normalized units (nu) }\end{array}$ & PNS \\
\hline & LFnu & $\begin{array}{l}\text { Spectral power in the low frequency range in normalized } \\
\text { units (nu) }\end{array}$ & SNS \\
\hline & $\mathrm{LF} / \mathrm{HF}$ & Ratio of percentage LF to percentage HF & $\begin{array}{l}\text { Sympathovagal } \\
\text { balance }\end{array}$ \\
\hline \multirow{2}{*}{ 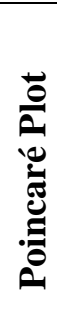 } & SD1 & $\begin{array}{l}\text { Standard deviation of instantaneous beat-to-beat } \\
\text { variability in msec }\end{array}$ & PNS \\
\hline & SD2 & $\begin{array}{l}\text { Standard deviation of continuous long-term variability in } \\
\text { msec }\end{array}$ & $\begin{array}{c}\text { SNS \& global HRV } \\
25\end{array}$ \\
\hline
\end{tabular}


Table 3 Comparison of baseline heart rate variability data between stimulant-free children with ADHD and control subjects

\begin{tabular}{|c|c|c|c|c|}
\hline & Indicator (unit) & $\begin{array}{l}\text { Stimulant-free } \\
\text { ADHD children }\end{array}$ & Controls & $\begin{array}{c}\text { Mann- } \\
\text { Whitney test }\end{array}$ \\
\hline & & Mean (SD) & Mean (SD) & p-value \\
\hline \multirow{5}{*}{ 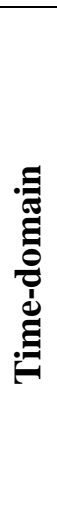 } & HR (bpm) & 87.67 (7.75) & 93.77 (9.90) & 0.0245 \\
\hline & STDRR (sec) & $0.052(0.020)$ & $0.036(0.021)$ & 0.0082 \\
\hline & $\begin{array}{c}\text { RR triangular } \\
\text { index }\end{array}$ & $0.10(0.031)$ & $0.070(0.035)$ & 0.0020 \\
\hline & STDHR (bpm) & $6.75(2.06)$ & $5.26(2.05)$ & 0.0193 \\
\hline & RMSSD (msec) & $52.51(21.95)$ & 35.99 (26.38) & 0.0157 \\
\hline \multirow{5}{*}{ 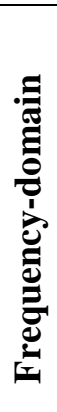 } & HF $\left(\mathrm{ms}^{2}\right)$ & $659.16(505.75)$ & 435.67 (595.03) & 0.0596 \\
\hline & $\mathrm{LF}\left(\mathrm{ms}^{2}\right)$ & $667.00(755.66)$ & 372.39 (541.41) & 0.0193 \\
\hline & HF (nu) & $51.94(16.82)$ & $53.75(14.70)$ & 0.9033 \\
\hline & LF (nu) & 48.06 (16.82) & 46.25 (14.70) & 0.9033 \\
\hline & LF/HF & $1.22(1.01)$ & $1.02(0.67)$ & 0.9033 \\
\hline \multirow{2}{*}{ 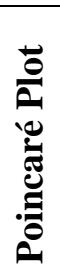 } & SD1 (msec) & 37.36 (15.59) & 25.63 (18.77) & 0.0157 \\
\hline & SD2 (msec) & 76.28 (26.86) & 53.43 (27.95) & 0.0057 \\
\hline
\end{tabular}

HR, heart rate; STDRR, standard deviation in the normal RR-interval; RR triangular index, base of the triangular area under the main peak of the RR interval frequency distribution diagram; STDHR, standard deviation of the selected heart rate series; RMSSD, square root of the mean squared differences of successive RR intervals; HF $\left(\mathrm{ms}^{2}\right)$, spectral power in the high frequency range; $\mathrm{LF}\left(\mathrm{ms}^{2}\right)$, spectral power in the low frequency range; HF (nu), spectral power in the high frequency range in normalized units; LF (nu), spectral power in the low frequency range in normalized units; LF/HF, ratio of percentage LF to percentage HF; SD1, standard deviation of instantaneous beat-to-beat variability; SD2, standard deviation of continuous long-term variability 
Table 4 Comparison of baseline heart rate variability data between children with ADHD on stimulants and control subjects

\begin{tabular}{|c|c|c|c|c|}
\hline & Indicator (unit) & $\begin{array}{c}\text { ADHD } \\
\text { children on } \\
\text { stimulants }\end{array}$ & Controls & $\begin{array}{c}\text { Mann-Whitney } \\
\text { test }\end{array}$ \\
\hline & & Mean (SD) & Mean (SD) & p-value \\
\hline \multirow{5}{*}{. } & HR (bpm) & 95.41 (11.03) & 93.77 (9.90) & 0.6268 \\
\hline & STDRR (sec) & $0.044(0.021)$ & $0.036(0.021)$ & 0.1619 \\
\hline & $\begin{array}{c}\text { RR triangular } \\
\text { index }\end{array}$ & $0.074(0.035)$ & $0.070(0.035)$ & 0.3781 \\
\hline & STDHR (bpm) & $6.29(2.09)$ & $5.26(2.05)$ & 0.0833 \\
\hline & RMSSD (msec) & $45.71(26.96)$ & 35.99 (26.38) & 0.1622 \\
\hline \multirow{5}{*}{ 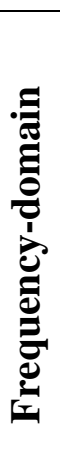 } & HF $\left(\mathrm{ms}^{2}\right)$ & $517.32(496.15)$ & 435.67 (595.03) & 0.3948 \\
\hline & $\mathrm{LF}\left(\mathrm{ms}^{2}\right)$ & $541.47(689.72)$ & $372.39(541.41)$ & 0.3782 \\
\hline & HF (nu) & $51.47(17.14)$ & $53.75(14.70)$ & 0.6928 \\
\hline & LF (nu) & $48.53(17.14)$ & 46.25 (14.70) & 0.6928 \\
\hline & $\mathbf{L F} / \mathbf{H F}$ & $1.24(1.02)$ & $1.02(0.67)$ & 0.6928 \\
\hline \multirow{2}{*}{ 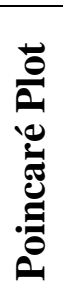 } & SD1 (msec) & 32.53 (19.17) & $25.63(18.77)$ & 0.1622 \\
\hline & SD2 (msec) & $68.83(28.22)$ & $53.43(27.95)$ & 0.0388 \\
\hline
\end{tabular}

HR, heart rate; STDRR, standard deviation in the normal RR-interval; RR triangular index, base of the triangular area under the main peak of the RR interval frequency distribution diagram; STDHR, standard deviation of the selected heart rate series; RMSSD, square root of the mean squared differences of successive RR intervals; HF $\left(\mathrm{ms}^{2}\right)$, spectral power in the high frequency range; $\mathrm{LF}\left(\mathrm{ms}^{2}\right)$, spectral power in the low frequency range; HF (nu), spectral power in the high frequency range in normalized units; LF (nu), spectral power in the low frequency range in normalized units; LF/HF, ratio of percentage LF to percentage HF; SD1, standard deviation of instantaneous beat-to-beat variability; SD2, standard deviation of continuous long-term variability 
Table 5 Comparison of baseline heart rate variability data between children with ADHD when on stimulants and when stimulant-free

\begin{tabular}{|c|c|c|c|c|}
\hline & \multirow[t]{2}{*}{ Indicator (unit) } & $\begin{array}{l}\text { ADHD children } \\
\text { on stimulants }\end{array}$ & $\begin{array}{l}\text { Stimulant-free } \\
\text { ADHD children }\end{array}$ & $\begin{array}{c}\text { Wilcoxon } \\
\text { test }\end{array}$ \\
\hline & & Mean (SD) & Mean (SD) & p-value \\
\hline \multirow{5}{*}{ 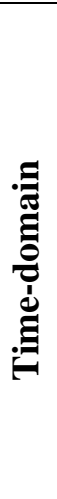 } & HR (bpm) & 95.41 (11.03) & $87.67(7.75)$ & 0.0033 \\
\hline & STDRR (sec) & $0.044(0.021)$ & $0.052(0.020)$ & 0.0421 \\
\hline & $\begin{array}{c}\text { RR triangular } \\
\text { index }\end{array}$ & $0.074(0.035)$ & $0.100(0.031)$ & 0.0033 \\
\hline & STDHR (bpm) & $6.29(2.09)$ & $6.75(2.06)$ & 0.4445 \\
\hline & RMSSD (msec) & $45.71(26.96)$ & $52.51(21.95)$ & 0.2514 \\
\hline \multirow{5}{*}{ 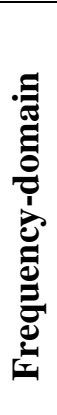 } & HF $\left(\mathrm{ms}^{2}\right)$ & $517.32(496.15)$ & $659.16(505.75)$ & 0.1590 \\
\hline & LF (ms $\left.{ }^{2}\right)$ & $541.47(689.72)$ & $667.00(755.66)$ & 0.0766 \\
\hline & HF (nu) & $51.47(17.14)$ & $51.94(16.82)$ & 0.9679 \\
\hline & LF (nu) & $48.53(17.14)$ & 48.06 (16.82) & 0.9679 \\
\hline & LF/HF & $1.24(1.02)$ & $1.22(1.01)$ & 0.9359 \\
\hline \multirow{2}{*}{ 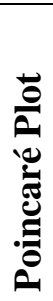 } & SD1 (msec) & 32.53 (19.17) & $37.36(15.59)$ & 0.2432 \\
\hline & SD2 (msec) & $68.83(28.22)$ & 76.28 (26.86) & 0.1589 \\
\hline
\end{tabular}

HR, heart rate; STDRR, standard deviation in the normal RR-interval; RR triangular index, base of the triangular area under the main peak of the RR interval frequency distribution diagram; STDHR, standard deviation of the selected heart rate series; RMSSD, square root of the mean squared differences of successive RR intervals; HF $\left(\mathrm{ms}^{2}\right)$, spectral power in the high frequency range; LF $\left(\mathrm{ms}^{2}\right)$, spectral power in the low frequency range; HF (nu), spectral power in the high frequency range in normalized units; LF (nu), spectral power in the low frequency range in normalized units; LF/HF, ratio of percentage LF to percentage HF; SD1, standard deviation of instantaneous beat-to-beat variability; SD2, standard deviation of continuous long-term variability 
Table 6 Comparison of baseline skin conductivity between the groups

\begin{tabular}{|c|c|c|c|}
\hline \multirow{2}{*}{$\begin{array}{l}\text { Indicator } \\
\text { (unit) }\end{array}$} & $\begin{array}{l}\text { Stimulant-free } \\
\text { ADHD children }\end{array}$ & Controls & $\begin{array}{c}\text { Mann- } \\
\text { Whitney test }\end{array}$ \\
\hline & Mean (SD) & Mean (SD) & p-value \\
\hline \multirow{7}{*}{$\begin{array}{c}\text { Baseline } \\
\text { skin } \\
\text { conductivity } \\
\text { ( } \mu \text { Mhos) }\end{array}$} & $1.35(0.83)$ & $1.96(1.00)$ & 0.0754 \\
\hline & $\begin{array}{l}\text { ADHD children } \\
\text { on stimulants }\end{array}$ & Controls & $\begin{array}{c}\text { Mann- } \\
\text { Whitney test }\end{array}$ \\
\hline & Mean (SD) & Mean (SD) & p-value \\
\hline & $2.21(1.14)$ & $1.96(1.00)$ & 0.5637 \\
\hline & $\begin{array}{l}\text { ADHD children } \\
\text { on stimulants }\end{array}$ & $\begin{array}{l}\text { Stimulant-free } \\
\text { ADHD } \\
\text { children }\end{array}$ & $\begin{array}{c}\text { Wilcoxon } \\
\text { test }\end{array}$ \\
\hline & Mean (SD) & Mean (SD) & p-value \\
\hline & $2.21(1.14)$ & $1.35(0.83)$ & 0.0055 \\
\hline
\end{tabular}




\section{Figure (below) Legends}

Figure 1 The effect of focussed attention on the high frequency component of heart rate variability in ADHD children on stimulants, stimulant-free ADHD children and control subjects

Figure 2 The effect of focussed attention on skin conductivity in ADHD children on stimulants, stimulant-free ADHD children and control subjects

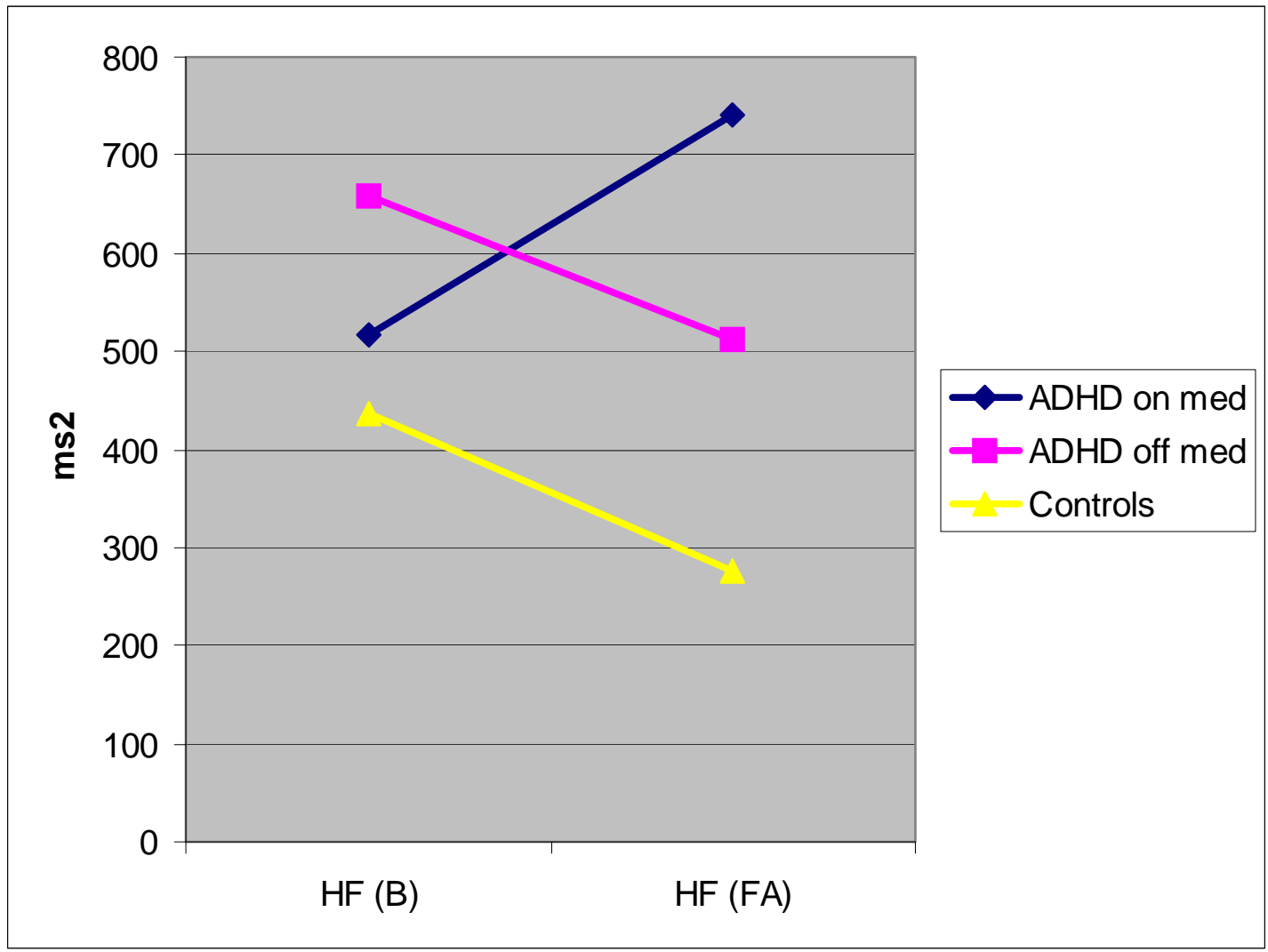

Figure 1 The effect of focussed attention on the high frequency component of heart rate variability in ADHD children on stimulants, stimulant-free ADHD children and control subjects HF (B): High frequency component of heart rate variability during baseline; HF (FA): High frequency component of heart rate variability during focussed attention 


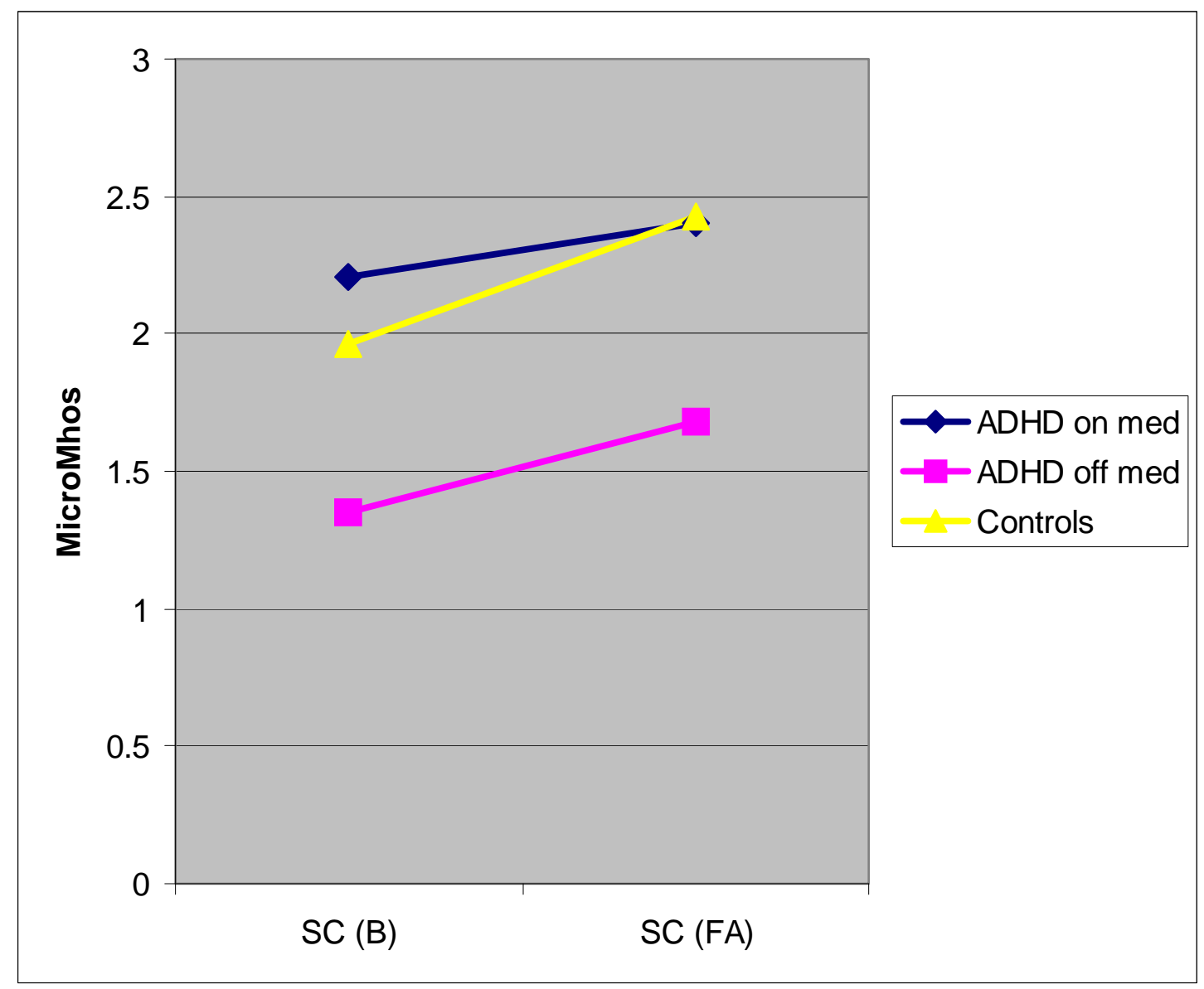

Figure 2 The effect of focussed attention on skin conductivity in ADHD children on stimulants, stimulant-free ADHD children and control subjects

SC (B): Skin conductivity during baseline; SC (FA): skin conductivity during focussed attention 